\title{
İki Kısımlı Tarife Kontratı ile Yeşil Endüstri 4.0 Tedarik Zincirinin Koordinasyonu
}

\author{
Coordination of a Green Industry 4.0 Supply Chain with a Two-Part Tariff Contract
}

\author{
Peral TOKTAŞ-PALUT ${ }^{\mathbf{1}}$ \\ ${ }^{I}$ Doğuş Üniversitesi, Endüstri Mühendisliği Bölümü, 34775, İstanbul, Türkiye
}

\begin{abstract}
Öz
Günümüzde çevresel koşulların bozulması nedeniyle, firmaların çevreye duyarlı üretim yapması gittikçe daha fazla önem kazanmaktadır. Bu bilinç tüketicileri de etkilemiş olup, yeşil ürünlere olan talep gün geçtikçe artmaktadır. Endüstri 4.0 teknolojilerinin de çevreye olumlu etkilerinin olduğu öngörülmektedir. Bu çalışma, Endüstri 4.0 teknolojileri uygulayan ve çevreye duyarlı bir pazara hizmet eden, iki aşamalı yeşil bir tedarik zincirinin koordinasyonunu ele almaktadır. Üreticinin Endüstri 4.0 yatırım miktarı, maliyetini ve yeşillik seviyesini etkilemektedir. Perakendeci de yeşillik seviyesini arttırmak için yatırım yapmaktadır. Tedarik zincirindeki her bir üyenin sadece kendi sistemini optimize etmeyi amaçladığ merkezkaç sistemde, üreticinin ve perakendecinin yeşillik seviyeleri optimal çözüme oranla daha düşük çıkmaktadır. Ayrıca, üreticinin Endüstri 4.0 yatırım seviyesi, talep ve tedarik zincirinin toplam karı da merkezkaç çözümde daha düşüktür. Bu sonuçlar, tedarik zincirinin koordine edilmesi gerektiğini göstermektedir. Bu amaçla, iki kısımlı tarife (IKT) kontratı geliştirilmiştir. İKT kontratında, üretici ürünleri maliyetine satmakta, perakendeci ise daha sonra üreticiye toplu bir ödeme yapmaktadır. Kontrat sonrasında hem üretici hem de perakendeci rasyonel olarak merkezi çözüm doğrultusunda karar vermektedir. Dolayısıyla, IKKT kontratı tedarik zincirinin koordinasyonunu sağlamaktadır. Buna ek olarak, Pareto iyileștiren olmasının yanı sıra, bu kontrat sayesinde üyeler adil bir kar artışından da faydalanabilmektedir. Kontrat öncesi ve sonrası tedarik zincirleri analiz edildiğinde, koordinasyonun tedarik zincirinin ekonomik ve çevresel sürdürülebilirliğini arttırdığı ortaya çıkmaktadır. Ayrıca, tedarik zinciri üyelerinin etkileşim içinde olduğu; üreticinin yeşillik seviyesindeki artışın, perakendecinin de daha fazla yeşillik yatırımı yapmasını sağladığı görülmektedir.
\end{abstract}

Anahtar kelimeler: Yeşil tedarik zinciri; Endüstri 4.0; Koordinasyon; Kontrat; Oyun teorisi.

\begin{abstract}
Due to the worsening environmental conditions, producing eco-friendly products is gaining more importance. This awareness has also affected the consumers so that green products are demanded more. Industry 4.0 technologies are also expected to have positive effects on the environment. This paper analyzes the coordination of a two-stage green supply chain that applies Industry 4.0 technologies and supplies products to a green-conscious market. The Industry 4.0 investment level of the manufacturer affects her cost and greening level. The retailer also invests in green processes. In the decentralized system, both members determine lower greening levels than the optimal solution. Also, the Industry 4.0 investment level of the manufacturer, demand, and overall supply chain profit are lower in the decentralized solution. These results indicate that the supply chain should be coordinated. Thus, a two-part tariff (TPT) contract is developed. In the TPT contract, the manufacturer sets the unit wholesale price equal to her unit cost, and then the retailer makes a lump-sum payment to the manufacturer. Both members act rationally according to the centralized solution after the contract. Thus, the TPT contract has coordination ability. Also, the contract is Pareto improving and fair so that both members can utilize fair profit increases. The analysis denotes that coordination increases the economic and environmental sustainability of the supply chain. Besides, the supply chain members interact with each other, and an increase in the greening level of the manufacturer also leads to an increase in the greening investment of the retailer. Keywords: Green supply chain; Industry 4.0; Coordination; Contract; Game theory.
\end{abstract}

\section{GİRiş}

Dördüncü Sanayi Devrimi ve dijital dönüşüm, tedarik zincirlerini Endüstri 4.0 teknolojilerini kullanmaya teşvik etmiştir. Bu teknolojiler arasında, büyük veri ve analitiği, otonom robotlar, eklemeli imalat, bulut, siber güvenlik, endüstriyel nesnelerin interneti, düşey ve yatay entegrasyon, yapay zeka ile makine öğrenmesi sayllabilir $[1,2]$. Endüstri 4.0 teknolojileri, tedarik zincirlerinin anlık ve doğru veri paylaşımını kolaylaştırı; koordinasyon kabiliyetlerini ve performanslarını arttırır. Kaynakların daha etkin kullanımı, verimliliğin artması, tedarik zincirleri üyeleri arasında daha etkin iş birliği, ürün geliştirme maliyetlerinin azalması ve daha kısa temin süreleri, bu teknolojilerin faydaları arasında yer almaktadır $[2,3]$. Endüstri 4.0 teknolojileri, ulaştırma, envanter yönetimi ve malzeme elleçleme gibi lojistik faaliyetlerin daha etkin yürütülmesini sağlar [4]. Bunların dışında, tedarik zincirlerinin daha yenilikçi, rekabetçi ve sürdürülebilir olması açısından da bu teknolojiler önemli bir role sahiptir $[5,6]$. 
Tedarik zincirlerinin sürdürülebilir olması günümüzde gittikçe daha fazla önem kazanmaktadır. Tedarik zincirleri, ekonomik dengenin yanı sıra, çevresel ve sosyal kaynakları daha etkin kullanmak için de çaba sarf etmektedir. Ekonomik sürdürülebilirlik uzun vadede ekonomik büyümeyi göz önüne almakta olup, çevresel ve sosyal sistemlere de zarar vermemelidir. Çevresel sürdürülebilirlik, ekolojik sistemi korumayı ve doğal kaynakların kullanımını dengelemeye çalışır. Sosyal sürdürülebilirlik ise, sosyal adalet, güvenlik ve sağlık hizmeti gibi insan haklarına odaklanarak insanlığın refahını korumayı amaçlar [7, 8, 9]. Bir tedarik zincirinin sürdürülebilir olması için bu üç boyutu da dikkate alması önemlidir. $\mathrm{Bu}$ bilinç tüketicileri de etkilemiş olup, daha sürdürülebilir ürün ve hizmetlere olan talep gün geçtikçe artmaktadır. Tedarik zinciri üyeleri arasındaki iş birliği de sürdürülebilirlik açısından önem taşımaktadır [10]. Bu durum, firmaların tedarik zincirlerinde yer alan diğer üyelerle iş birliklerini arttırmıştır [11]. Tedarik zincirlerinin koordinasyonu, Endüstri 4.0 ortamında sürdürülebilirliğin artması açısından daha da öne çıkmaktadır [12]. Koordinasyonu sağlamanın yollarından biri, üyeler arasında kontratlar geliştirmektir. Bir tedarik zincirinde tek bir karar verici sistemin tamamını optimize etmeyi amaçlıyorsa, bu tedarik zinciri merkezi olarak adlandırılır. Merkezkaç tedarik zincirinde ise her üye kendi sistemini optimize etmeye odaklanır. Merkezi ve merkezkaç çözümler genellikle birbirinden farklıdır. Ancak, bu çözümler kontratlar aracılı̆̆ ile birbirine eşitlenebilir ve tedarik zincirinin koordinasyonu sağlanmış olur. Bir kontratın koordinasyon yeteneğinin yanı sıra, Pareto iyileştiren olması da önem taşımaktadır. Üyelerden birinin durumu iyileşirken, hiçbir üyenin durumu daha kötüye gitmiyorsa, söz konusu kontrat Pareto iyileştiren olarak adlandırılır. Aksi halde, kontrat, üyeler tarafindan kabul edilebilir ve uygulanabilir olmaz [13].

Bu makale, Endüstri 4.0 teknolojileri uygulayan yeşil bir tedarik zincirinin koordinasyonunu ele almaktadır. Tedarik zinciri iki aşamalı olup, bir üretici ve bir perakendeciden oluşmaktadır. Üretici, Endüstri 4.0 teknolojileri uygulamaktadır; yaptığı yatırım miktarı, maliyetini ve yeşillik seviyesini etkilemektedir. Perakendeci de yeşillik seviyesini arttırmak için yatırım yapmaktadır. Pazar, perakende fiyatının yanı sıra hem üreticinin hem de perakendecinin yeşillik seviyesine duyarlıdır. Bu çalışmadaki araştırma soruları aşağıda verilmiştir:

1. Tedarik zincirinin merkezi ve merkezkaç çözümleri nedir?

2. İki kısımlı tarife kontratı ile tedarik zincirinin koordinasyonu mümkün müdür?

3. Bu kontrat Pareto iyileştiren midir?

$\mathrm{Bu}$ araştırma sorularını cevaplamak için oyun teorisi yaklaşımı kullanılarak analitik çözümler elde edilmiş ve yönetimsel çıkarımlar yapılmıştır. $\mathrm{Bu}$ çalışma, Endüstri 4.0 yatırımı ile sürdürülebilirliğin ekonomik ve çevresel boyutlarını ilişkilendirmesi açısından kontrat literatüründeki önemli bir boşluğu doldurmaktadır. Üreticinin maliyetinin ve yeşillik seviyesinin Endüstri 4.0 yatırımına bağlı olarak modellenmesi ve her iki üyenin de yeşillik seviyesini arttırmak için yatırım yapması, bu makalede kurulan modeli diğer çalışmalardan ayırmaktadır.

Makalenin organizasyonu şu şekildedir. İkinci bölümde ilgili literatüre yer verilmiştir. Merkezi ve merkezkaç modeller ile çözümleri üçüncü bölümde yer almaktadır. Tedarik zincirinin koordinasyonu için tasarlanan iki kısımlı tarife kontratı dördüncü bölümde verilmiştir. Beşinci bölümde, elde edilen sonuçların yorumlanması için sayısal bir analiz yapılmıştır. Sonuçlar, altıncı bölümde yer almaktadır.

\section{LITERATÜR TARAMASI}

$\mathrm{Bu}$ çalışma, hem Endüstri 4.0 teknolojileri uygulayan, hem de çevreye duyarlı olup yeşillik yatırımı yapan bir tedarik zincirinin koordinasyonunu ele almaktadır. Buna bağlı olarak, bu bölümde, yeşil, sosyal sorumlu ya da sürdürülebilir tedarik zincirlerini koordine etmek amacıyla kontratlar geliştiren çalışmalara değinilecektir. Bu çalışmalar arasında çok azı Endüstri 4.0 teknolojilerini de dikkate almaktadır.

Tedarik zincirlerinin kontratlar aracılığı ile koordinasyonu literatürde önemli bir yere sahiptir [14]. Bu konu ile ilgili detaylı literatür taramaları Govindan vd. [15], Chauhan ve Singh [16] ile Bart vd. [17]'nde bulunabilir. Sürdürülebilirliğin çeşitli boyutlarını da dikkate alan koordinasyon çalışmalarının çoğu iki aşamalı yeşil tedarik zincirlerine odaklanmaktadır. Bu çalışmalarda, tedarik zinciri üyelerinden en az biri yeşillik yatırımı yapmaktadır. Çoğu çalışmada oyun teorisi yaklaşımı kullanılmıştır. Pazar talebi, genellikle perakende fiyatı ve yeşillik seviyesinin bir fonksiyonudur. Toptan satış fiyatı [18], maliyet paylaşımı $[18,19,20]$, gelir paylaşımı $[20,21,22,23]$ ve iki kısımlı tarife [24, 25] kontratları en çok uygulanan kontratlardır. Bu çalışmaların yanı sıra, sosyal sorumlu $[26,27]$, hem yeşil hem sosyal sorumlu $[28,29,30]$ veya sürdürülebilir $[31,32,33]$ tedarik zincirlerinin koordinasyonunu ele alan çalışmalar da bulunmaktadır. Bu çalışmalarda da tedarik zinciri üyelerinden biri ya da her ikisi birden kurumsal sosyal sorumluluk ya da sürdürülebilirlik yatırımı yapmaktadır. Pazar talebi, genellikle perakende fiyatı ve kurumsal sosyal sorumluluk ya da sürdürülebilirlik seviyesinin bir fonksiyonudur. En çok uygulanan kontratlar, toptan satış fiyatı [26], maliyet paylaşımı [29], gelir paylaşımı [27, 31, 32, 34] ve iki kısımlı tarife $[31,34]$ kontratlarıdır. Bunların dışında, daha az sayıda çalışma üç aşamalı tedarik zincirlerine odaklanmaktadır [35, 36, 37, 38]. Bu konu ile ilgili daha detaylı literatür taraması Toktaş-Palut [38]'ta bulunabilir.

Yukarıda bahsedilen çalışmaların yanı sıra, hem Endüstri 4.0 teknolojileri uygulayan hem de sürdürülebilirlik bilinci olan tedarik zincirlerinin 
koordinasyonunu ele alan çalışma sayısı son derece azdır. Ghosh vd. [39], Endüstri 4.0 ortamında önem kazanan çevresel bilince sahip iki aşamalı bir tedarik zincirini ele almış ve maliyet paylaşımı kontratı geliştirmiştir. Söz konusu çalışmada, fiyat kazancı ve rekabetin de etkileri incelenmiştir. Ma vd. [40], Endüstri 4.0 ortamında emisyon üst sınırı ve ticareti sistemi altında üç aşamalı bir soğuk tedarik zincirini ele alarak, gelir ve maliyet paylaşımı kontratı tasarlamıştır. Araştırmacılar, ayrıca karbon vergisi politikasını da analiz etmiştir. Söz konusu iki çalışma da bu makale ile aynı kapsamda yer almakla birlikte, her ikisi de Endüstri 4.0 yatırımı ile yeşillik seviyesini ilişkilendirmemiştir. Üreticinin maliyetinin ve yeşillik seviyesinin Endüstri 4.0 yatırımına bağlı olarak modellenmesi ve her iki üyenin de yeşillik seviyesini arttırmak için yatırım yapması, bu makalede kurulan modeli diğer çalışmalardan ayırmakta ve literatürdeki önemli bir boşluğu doldurmaktadır.

\section{MODELLER}

$\mathrm{Bu}$ makale, Endüstri 4.0 teknolojileri uygulayan ve çevreye duyarlı bir pazara hizmet eden yeşil bir tedarik zincirini ele almaktadır. Tedarik zinciri iki aşamalıdır; bir üretici ve bir perakendeciden oluşmaktadır. Üretici, ürünleri Endüstri 4.0 teknolojisi ile üretmekte olup, Endüstri 4.0 yatırım seviyesi $\alpha$ olarak verilmiştir. Üreticinin birim baz maliyeti $c$ olmakla birlikte, birim maliyeti Endüstri 4.0 yatırımına bağlı olarak azalmaktadır [41, 42, 43]. Buna göre, üreticinin birim maliyeti, $c(\alpha)=c-h_{2} \alpha$ şeklinde azalan bir doğrusal fonksiyon olarak modellenmiştir. Burada, $h_{2}>0$, üreticinin Endüstri 4.0 yatırım seviyesine bağlı birim maliyetindeki azalış miktarıdır. Üreticinin Endüstri 4.0 yatırım maliyeti ise $E \alpha^{2}$ şeklinde artan bir kuadratik fonksiyon olarak modellenmiştir [44]. Burada, $E>0$, üreticinin Endüstri 4.0 yatırım parametresidir. Üreticinin Endüstri 4.0 yatırımı aynı zamanda yeşillik seviyesini de pozitif yönde etkilemektedir [45, 46, 47, 48, 49]. Bu bağlamda, üreticinin yeşillik seviyesi, $\theta=h_{1} \alpha$ şeklinde artan bir doğrusal fonksiyon olarak modellenmiştir. Burada, $h_{1}>0$, üreticinin Endüstri 4.0 yatırım seviyesinin yeşillik seviyesine birim etkisini ifade etmektedir. Üreticinin birim toptan satış fiyatı ise $w$ olarak verilmiştir. Perakendeci, ürünleri üreticiden satın almakta ve pazara satmaktadır. Perakendecinin birim sabit ve değişken maliyeti ihmal edilebilir düzeydedir; birim perakende fiyatı ise $p$ ile gösterilmektedir. Perakendeci, ürünlerin pazarlanması aşamasında çevreye duyarlı davranmakta ve yeşillik yatırımı yapmaktadır. Perakendecinin yeşillik seviyesi $\beta$ olarak verilmiştir. Perakendecinin yeşillik yatırım maliyeti ise $I \beta^{2}$ şeklinde artan bir kuadratik fonksiyon olarak modellenmiştir. Burada, $I>0$, perakendecinin yeşillik yatırım parametresidir. Pazar, perakende fiyatı ile perakendeci ve üreticinin yeşillik seviyelerine duyarlıdır. Buna göre, pazar talebi, $D=a-b p+g_{P} \beta+g_{U} \theta$ olarak modellenmiştir. Burada, $a, b, g_{P}, g_{U}>0$ olup, potansiyel pazar büyüklüğü $a$; tüketicinin perakende fiyatına duyarlılığı $b$; tüketicinin perakendecinin ve üreticinin yeşillik seviyelerine duyarlılıkları ise sırasıyla $g_{P}$ ve $g_{U}$ olarak verilmiştir. Üreticinin yeşillik seviyesi fonksiyonu talep fonksiyonunda yerine konulduğunda $D=a-b p+g_{P} \beta+g_{U} h_{1} \alpha$ elde edilir. Bu makalede kullanılan notasyon Tablo 1'de görülebilir.

Tablo 1. Notasyon

\begin{tabular}{lll}
\hline & Notasyon & Tanım \\
\hline Parametreler & $a$ & Potansiyel pazar büyüklüğü \\
& $c$ & Tüketicinin perakende fiyatına duyarlılığı \\
$E$ & Üreticinin birim baz maliyeti \\
$g_{P}$ & Üreticinin Endüstri 4.0 yatırım parametresi \\
$g_{U}$ & Tüketicinin perakendecinin yeşillik seviyesine duyarlılığı \\
$h_{1}$ & Ürketicinin üreticinin yeşillik seviyesine duyarlılığı \\
& $h_{2}$ & Üreticinin Endüstri 4.0 yatırım seviyesine bağlı birim maliyetindeki azalı̧̧ \\
$I$ & Perakendecinin yeşillik yatırım parametresi \\
$D$ & Pazar talebi \\
$p$ & Birim perakende fiyatı \\
$T$ & İki kisımlı tarife kontratında perakendecinin üreticiye yaptığ toplu ödeme \\
$w$ & Üreticinin birim toptan satış fiyatı \\
$\alpha$ & Üreticinin Endüstri 4.0 yatırım seviyesi \\
$\beta$ & Perakendecinin yeşillik seviyesi \\
$\theta$ & Üreticinin yeşillik seviyesi \\
$\pi_{(\cdot)}$ & Tedarik zinciri üyesinin karı (P: Perakendeci; $U:$ Üretici) \\
$\pi_{T Z}$ & Tedarik zincirinin toplam karı \\
&
\end{tabular}


Merkezi ve merkezkaç modellere geçmeden önce, bu çalışmada yapılan varsayımlar aşağıda listelenmiştir:

Varsayım 1. Üreticinin Endüstri 4.0 yatırım seviyesi ve perakendecinin yeşillik seviyesinin pozitif olmasını garanti etmek için aşağıdaki varsayımlar yapılmıştır:

a. $E\left(4 I b-g_{p}^{2}\right)-I\left(g_{U} h_{1}+b h_{2}\right)^{2}>0$;

b. $a-b c>0$.

Varsayım 2. Üreticinin birim maliyetinin pozitif olmasını garanti etmek için $c-h_{2} \alpha>0$ varsayımı yapılmıştır.

\subsection{Merkezi Model}

Merkezi modelde, tedarik zincirinin toplam karını maksimize etmeyi amaçlayan tek bir karar verici bulunmaktadır. Karar değişkenleri, perakende fiyatı, perakendecinin yeşillik seviyesi ve üreticinin Endüstri 4.0 yatırım seviyesidir. Perakendecinin (P) ve üreticinin (U) kar fonksiyonları $\pi_{(\cdot)}(\cdot)$ sirasıyla

$$
\begin{aligned}
& \pi_{P}(p, \beta)=(p-w) D-I \beta^{2}, \\
& \pi_{U}(w, \alpha)=\left(w-c+h_{2} \alpha\right) D-E \alpha^{2}
\end{aligned}
$$

olarak verilmiştir. Buna göre, tedarik zincirinin (TZ) toplam karı şu şekildedir:

$\pi_{T Z}(p, \beta, \alpha)=\pi_{p}(\cdot)+\pi_{U}(\cdot)=\left(p-c+h_{2} \alpha\right) D-I \beta^{2}-E \alpha^{2}$.

Burada, $D=a-b p+g_{P} \beta+g_{U} h_{1} \alpha$.

Merkezi modelin çözümünde oyun teorisi yaklaşımı kullanılmıştır. Tedarik zincirindeki karar verici, birinci aşamada, beklenen perakende fiyatı ve perakendecinin yeşillik seviyesini dikkate alarak, üreticinin Endüstri 4.0 yatırım seviyesini $(\alpha)$ belirlemektedir. İkinci aşamada ise, perakende fiyatı $(p)$ ile perakendecinin yeşillik seviyesine $(\beta)$ eş zamanlı olarak karar vermektedir. Merkezi model, geriye dönük tümevarım yöntemi ile çözülmüş ve aşağıdaki önerme elde edilmiştir.

Önerme 1. Merkezi tedarik zincirinin tek alt-oyun mükemmel Nash dengesi şu şekildedir:

$$
\begin{aligned}
& p^{*}=\frac{E\left(2 I(a+b c)-c g_{P}^{2}\right)-I\left(g_{U} h_{1}+b h_{2}\right)\left(c g_{U} h_{1}+a h_{2}\right)}{E\left(4 I b-g_{P}^{2}\right)-I\left(g_{U} h_{1}+b h_{2}\right)^{2}}, \\
& \beta^{*}=\frac{E g_{P}(a-b c)}{E\left(4 I b-g_{P}^{2}\right)-I\left(g_{U} h_{1}+b h_{2}\right)^{2}}, \\
& \alpha^{*}=\frac{I\left(g_{U} h_{1}+b h_{2}\right)(a-b c)}{E\left(4 I b-g_{P}^{2}\right)-I\left(g_{U} h_{1}+b h_{2}\right)^{2}} .
\end{aligned}
$$

Buna göre, üreticinin denge yeşillik seviyesi $\theta^{*}=h_{1} \alpha^{*}$ olarak bulunur. Merkezi tedarik zincirine ait denge toplam kar ve talep ise sırasıyla aşağıda verilmiştir:

$$
\begin{aligned}
& \pi_{T Z}^{*}=\frac{E I(a-b c)^{2}}{E\left(4 I b-g_{P}^{2}\right)-I\left(g_{U} h_{1}+b h_{2}\right)^{2}}, \\
& D^{*}=\frac{2 E I b(a-b c)}{E\left(4 I b-g_{P}^{2}\right)-I\left(g_{U} h_{1}+b h_{2}\right)^{2}} .
\end{aligned}
$$

$\mathrm{Bu}$ makalede yer alan tüm önermelerin ispatları Ek A'da bulunabilir.

\subsection{Merkezkaç Model}

Merkezkaç modelde, tedarik zincirinin her bir üyesi kendi sistemini optimize etmeyi amaçlamaktadır. Perakendeci ve üreticinin kar fonksiyonları sırasıyla Eşitlik (1) ve (2)'de verilmiştir. Merkezkaç modelin çözümünde oyun teorisi yaklaşımı kullanılmıştır. Oyunun ilk aşamasında, üretici, perakendecinin beklenen kararlarını dikkate alarak, birim toptan satış fiyatı $(w)$ ile Endüstri 4.0 yatırım seviyesine $(\alpha)$ eş zamanlı olarak karar vermektedir. İkinci aşamada ise, perakendeci, perakende fiyatı $(p)$ ile yeşillik seviyesini $(\beta)$ eş zamanlı olarak belirlemektedir. Merkezkaç model, geriye dönük tümevarım yöntemi ile çözülmüş ve aşağıdaki önerme elde edilmiştir.

Önerme 2. Merkezkaç tedarik zincirinin tek alt-oyun mükemmel Nash dengesi şu şekildedir:

$$
\begin{aligned}
& p^{m}=\frac{E\left(2 I b(3 a+b c)-g_{P}^{2}(a+b c)\right)-I b\left(g_{U} h_{1}+b h_{2}\right)\left(c g_{U} h_{1}+a h_{2}\right)}{b\left(2 E\left(4 I b-g_{P}^{2}\right)-I\left(g_{U} h_{1}+b h_{2}\right)^{2}\right)}, \\
& \beta^{m}=\frac{E g_{P}(a-b c)}{2 E\left(4 I b-g_{P}^{2}\right)-I\left(g_{U} h_{1}+b h_{2}\right)^{2}}, \\
& w^{m}=\frac{E\left(4 I b-g_{P}^{2}\right)(a+b c)-I b\left(g_{U} h_{1}+b h_{2}\right)\left(c g_{U} h_{1}+a h_{2}\right)}{b\left(2 E\left(4 I b-g_{P}^{2}\right)-I\left(g_{U} h_{1}+b h_{2}\right)^{2}\right)}, \\
& \alpha^{m}=\frac{I\left(g_{U} h_{1}+b h_{2}\right)(a-b c)}{2 E\left(4 I b-g_{P}^{2}\right)-I\left(g_{U} h_{1}+b h_{2}\right)^{2}} .
\end{aligned}
$$

Buna göre, üreticinin denge yeşillik seviyesi $\theta^{m}=h_{1} \alpha^{m}$ olarak bulunur. Merkezkaç tedarik zincirine ait denge toplam kar ve talep ise sırasıyla aşağıda verilmiştir:

$$
\begin{aligned}
\pi_{T Z}^{m} & =\frac{E I(a-b c)^{2}\left(3 E\left(4 I b-g_{P}^{2}\right)-I\left(g_{U} h_{1}+b h_{2}\right)^{2}\right)}{\left(2 E\left(4 I b-g_{P}^{2}\right)-I\left(g_{U} h_{1}+b h_{2}\right)^{2}\right)^{2}}, \\
D^{m} & =\frac{2 E I b(a-b c)}{2 E\left(4 I b-g_{P}^{2}\right)-I\left(g_{U} h_{1}+b h_{2}\right)^{2}} .
\end{aligned}
$$

\subsection{Merkezi ve Merkezkaç Çözümlerin Kiyaslanması}

Merkezi ve merkezkaç çözümler elde edildikten sonra bu çözümlerin kıyaslanması, kontrat tasarımı açısından önemlidir. Örneğin, üretici, merkezi çözümde Endüstri 4.0 teknolojilerine daha fazla yatırım yapıyorsa, hazırlanacak kontrat sonrasinda rasyonel olarak bu 
yatırım seviyesini belirlemelidir. Diğer bir deyişle, kontrat sonrasında merkezi ve merkezkaç çözümler birbirine eşit olmalıdır.

Önerme 3. Merkezi ve merkezkaç çözümlerin kıyaslanması sonucunda aşağıdaki bulgular elde edilmiştir:

a. Üreticinin Endüstri 4.0 yatırım ve yeşillik seviyeleri, merkezi çözümde daha yüksektir. Diğer bir deyişle, $\alpha^{*}>\alpha^{m}$ ve $\theta^{*}>\theta^{m}$.

b. Perakendecinin yeşillik seviyesi, merkezi çözümde daha yüksektir. Diğer bir deyişle, $\beta^{*}>\beta^{m}$.

c. Perakende fiyat1, $E\left(2 I b-g_{P}^{2}\right)-I g_{U} h_{1}\left(g_{U} h_{1}+b h_{2}\right)>0$ için merkezi çözümde daha düşüktür. Diğer bir deyişle, bu koşul sağlandığında $p^{*}<p^{m}$ olur. Aksi halde, $p^{*} \geq p^{m}$.

d. Talep, merkezi çözümde daha yüksektir. Diğer bir deyişle, $D^{*}>D^{m}$.

e. Tedarik zincirinin toplam karı, merkezi çözümde daha yüksektir. Diğer bir deyişle, $\pi_{T Z}^{*}>\pi_{T Z}^{m}$.

Önerme 3'e göre, tedarik zincirinin merkezkaç yapıda hareket etmesi, üreticinin Endüstri 4.0 yatırım seviyesi ve buna bağlı olarak yeşillik seviyesi ile perakendecinin yeşillik seviyesini olumsuz yönde etkilemektedir. Perakende fiyatı, $E\left(2 I b-g_{P}^{2}\right)-I g_{U} h_{1}\left(g_{U} h_{1}+b h_{2}\right)>0$ olmas1 durumunda merkezkaç tedarik zincirinde daha yüksektir. Bu durum, tüketicileri ekonomik açıdan olumsuz yönde etkilemektedir. Talep ise her koşulda merkezkaç sistemde daha düşüktür. Diğer bir deyişle, tedarik zinciri üyelerinin koordine olmaması, tüketicilerin bu zincirin sunduğu ürünlere olan talebini azaltmaktadır. Son olarak, tedarik zincirinin toplam karı da merkezkaç yapıdan olumsuz yönde etkilenmektedir. Bu kıyaslama, tedarik zincirinin koordine edilerek merkezi çözüme ulaşmasının, hem sürdürülebilirliğin ekonomik ve çevresel boyutları açısından, hem de Endüstri 4.0 teknolojilerine yapılan yatırımların artması açısından önemini ortaya koymaktadır.

\section{MERKEZKAÇ TEDARIKK ZINCIRINIIN KOORDİNASYONU}

Bu makalede, merkezkaç tedarik zincirinin koordine edilmesi amaciyla iki kısımlı tarife (IKT) kontratı geliştirilmiştir. IKT kontratı, tekelci ya da tekele yakın piyasalar için uygun bir kontrattır. Bu kontratta, üretici ürünleri maliyetine satmakta, perakendeci ise daha sonra üreticiye toplu bir ödeme yapmaktadır. Kontrat sonrasında hem üretici hem de perakendeci rasyonel olarak merkezi çözüm doğrultusunda karar vermelidir. $\mathrm{Bu}$ durumda, kontrat tedarik zincirinin koordinasyonunu sağlamaktadır. Bir kontratın koordinasyon yeteneğinin yanı sıra, Pareto iyileştiren olması da önem taşımaktadır. Üyelerden birinin durumu iyileşirken, hiçbir üyenin durumu daha kötüye gitmiyorsa, söz konusu kontrat Pareto iyileştiren olarak adlandirılır. Aksi halde, kontrat üyeler tarafindan kabul edilebilir ve uygulanabilir olmaz [13].

İKT kontratına göre, üreticinin birim toptan satış fiyatı birim maliyetine eşittir. Diğer bir deyişle, $w^{T}=c-h_{2} \alpha+\frac{E \alpha^{2}}{D}$. Perakendeci ise daha sonra üreticiye toplu bir ödeme yapmaktadır. Buna göre, perakendeci ve üreticinin kontrat sonrası kar fonksiyonları sırasıyla şu şekildedir:

$$
\begin{aligned}
& \pi_{P}^{T}(p, \beta)=(p-w) D-I \beta^{2}-T(\cdot) \\
& \pi_{U}^{T}(w, \alpha)=\left(w-c+h_{2} \alpha\right) D-E \alpha^{2}+T(\cdot) .
\end{aligned}
$$

Burada, $\quad D=a-b p+g_{P} \beta+g_{U} h_{1} \alpha \quad$ olup, $\quad T$ ise perakendecinin üreticiye yaptığı toplu ödemeyi göstermektedir.

Önerme 4. Aşağıda verilen toplu ödeme fonksiyonu için İKT kontratı tedarik zincirini koordine etmektedir:

$T(p, \beta, w, \alpha)=k_{1} p+k_{2} \beta+k_{3} w+k_{4} \alpha+\varepsilon$.

Burada,

$$
\begin{aligned}
& k_{1}=\frac{I\left(g_{U} h_{1}+b h_{2}\right)^{2}(a-b c)}{2\left(E\left(4 I b-g_{P}^{2}\right)-I\left(g_{U} h_{1}+b h_{2}\right)^{2}\right)}, \\
& k_{2}=-\frac{I g_{P}\left(g_{U} h_{1}+b h_{2}\right)^{2}(a-b c)}{2 b\left(E\left(4 I b-g_{P}^{2}\right)-I\left(g_{U} h_{1}+b h_{2}\right)^{2}\right)}, \\
& k_{3}=-\frac{2 E I b(a-b c)}{E\left(4 I b-g_{P}^{2}\right)-I\left(g_{U} h_{1}+b h_{2}\right)^{2}}, \\
& k_{4}=\frac{I g_{U} h_{1}\left(4 E b-\left(g_{U} h_{1}+b h_{2}\right)^{2}\right)(a-b c)}{2 b\left(E\left(4 I b-g_{P}^{2}\right)-I\left(g_{U} h_{1}+b h_{2}\right)^{2}\right)}
\end{aligned}
$$

olup, $\varepsilon$ ise hata terimidir. Buna göre, üretici rasyonel olarak birim toptan satış fiyatını $w^{T}=c-h_{2} \alpha^{*}+\frac{E \alpha^{* 2}}{D^{*}}$ olarak belirlemektedir.

Önerme 4'e göre, İKT kontratı sonrasında hem üretici hem de perakendeci rasyonel olarak merkezi çözüm doğrultusunda karar vermektedir. Dolayısıyla, söz konusu kontrat tedarik zincirini koordine etmektedir. Ancak daha önce de belirtildiği gibi, kontratın uygulanabilir olması için kontrat aynı zamanda Pareto iyileştiren de olmalıdır. 
Önerme 5. İKT kontratı, ancak ve ancak aşağıda verilen koşulların sağlanması durumunda Pareto iyileştirendir:

$$
\begin{gathered}
\varepsilon \leq \frac{I\left(2 E b(a+b c)-a\left(g_{U} h_{1}+b h_{2}\right)^{2}\right)(a-b c)}{2 b\left(E\left(4 I b-g_{P}^{2}\right)-I\left(g_{U} h_{1}+b h_{2}\right)^{2}\right)} \\
-\frac{E^{2} I\left(4 I b-g_{P}^{2}\right)(a-b c)^{2}}{\left(2 E\left(4 I b-g_{P}^{2}\right)-I\left(g_{U} h_{1}+b h_{2}\right)^{2}\right)^{2}}, \\
\varepsilon \geq \frac{E I(a-b c)^{2}}{2 E\left(4 I b-g_{P}^{2}\right)-I\left(g_{U} h_{1}+b h_{2}\right)^{2}} \\
-\frac{I\left(a\left(g_{U} h_{1}+b h_{2}\right)^{2}-4 E b^{2} c\right)(a-b c)}{2 b\left(E\left(4 I b-g_{P}^{2}\right)-I\left(g_{U} h_{1}+b h_{2}\right)^{2}\right)} .
\end{gathered}
$$

Burada, $\varepsilon$, Eşitlik (17)'de verilen toplu ödeme fonksiyonunda yer alan hata terimidir.

Önerme 3, 4 ve 5 uyarınca, İKT kontratı sonrasında perakendeci ve üretici rasyonel olarak merkezi çözüm doğrultusunda davranmaktadır. Dolayısıyla, tedarik zincirinin bütünü, hem sürdürülebilirliğin ekonomik ve çevresel boyutları açısından, hem de Endüstri 4.0 yatırımının artması açısından daha iyi bir konuma geçmektedir. Bunun yanı sıra, kontrat parametrelerinin uygun belirlenmesi durumunda İKT kontratı Pareto iyileştiren olup, her iki üyenin de kontrat sonrası karının artmasını garanti etmektedir. Bu durumda, her iki üye için de kontrat cazip hale gelmekte ve uygulanabilir olmaktadır.

\section{SAYISAL ANALİZ}

Bu bölümde, önceki bölümlerde elde edilen sonuçları sayısal olarak göstermek ve yönetimsel çıkarımlar yapmak için sayısal bir analiz yapılmıştır. Başlangıç parametreleri şu şekilde belirlenmiştir: $a=500, b=10$, $c=10, \quad E=40, \quad g_{P}=4, \quad g_{U}=5, \quad h_{1}=0,60, \quad h_{2}=0,80$, $I=50$. Buna göre, Tablo 2'de verilen sayısal analiz sonuçlarından da görüleceği gibi, İKT kontratı sonrasında tedarik zinciri üyeleri rasyonel olarak merkezi çözüme göre davranmaktadır. Merkezi ve merkezkaç çözümler kıyaslandığında, Önerme 3 'te belirtildiği üzere, tedarik zincirinin toplam karı ve talebin yanı sıra, üreticinin Endüstri 4.0 yatırım seviyesi ve buna bağlı olarak yeşillik seviyesi ile perakendecinin yeşillik seviyesi koordinasyon durumunda artmaktadır. Perakende fiyatı merkezi sistemde daha düşük olup, tedarik zincirinin koordinasyonu tüketicilerin satın alma gücünü olumlu yönde etkilemektedir.

İKT kontratı için iki ayrı durum analiz edilmiştir. İlk durumda $\varepsilon$ değeri, Eşitlik (18) ve (19)'da verilen üst ve alt sınırların ortalamasına eşit alınmıştır. Bu durumda, İKT kontratı Pareto iyileştirendir. Perakendecinin karı kontrat sonrasında yaklaşık \%54, üreticinin karı ise yaklaşık \%28 artmaktadır. İkinci durumda ise $\varepsilon$ değeri daha adil bir kar artışı olacak şekilde belirlenmiştir. Bu durumda ise hem tedarik zincirinin toplam karı hem de üyelerin karları yaklaşık \%37 oranında artmaktadır. Dolayısıyla, ikinci durumda belirlenen parametreler sonucunda Pareto iyileştiren olmasinın yanı sira, aynı zamanda adil bir kontrat elde edilmiştir.

Tablo 2. Sayısal analiz sonuçları

\begin{tabular}{lllll}
\hline & Merkezkaç & Merkezi & $\begin{array}{l}\text { İKT kontrat1 } \\
\text { (Durum 1) }\end{array}$ & $\begin{array}{l}\text { İKT kontrat1 } \\
\text { (Durum 2) }\end{array}$ \\
\hline$p$ & 40,1199 & 29,4244 & 29,4244 & 29,4244 \\
$\beta$ & 0,4192 & 0,8730 & 0,8730 & 0,8730 \\
$w$ & 29,6397 & - & 9,2498 & 9,2498 \\
$\alpha$ & 1,4410 & 3,0010 & 3,0010 & 3,0010 \\
$\theta$ & 0,8646 & 1,8006 & 1,8006 & 1,8006 \\
$D$ & 104,8012 & 218,2513 & 218,2513 & 218,2513 \\
$T$ & - & - & 2685,7534 & 2872,0789 \\
$\pi_{P}$ & 1089,5426 & - & 1679,2719 & 1492,9464 \\
$\pi_{U}$ & 2096,0241 & - & 2685,7534 & 2872,0789 \\
$\pi_{T Z}$ & 3185,5667 & 4365,0252 & 4365,0252 & 4365,0252 \\
$\pi_{P} \operatorname{artış1(\% )}$ & - & - & 54,1263 & 37,0251 \\
$\pi_{U} \operatorname{artıș~(\% )~}$ & - & - & 28,1356 & 37,0251 \\
$\pi_{T Z} \operatorname{artış1(\% )}$ & - & 37,0251 & 37,0251 & 37,0251 \\
\hline
\end{tabular}

Başlangıç parametreleri kullanılarak merkezi, merkezkaç ve kontrat sonrası sistemlerin analiz edilmesinin ardından, üreticinin Endüstri 4.0 yatırım seviyesinin yeşillik seviyesine birim etkisi $\left(h_{1}\right)$ ve üreticinin Endüstri 4.0 yatırım seviyesine bağlı birim maliyetindeki azalış miktarı $\left(h_{2}\right)$ temel alınarak duyarlılık analizleri yapılmıştır. Duyarlılık analizinde, $h_{1}$ ve $h_{2}$ değerleri şu aralıkta belirlenmiştir: $h_{1} \in(0,1]$ ve $h_{2} \in(0,1]$. 
Şekil 1'de, üreticinin Endüstri 4.0 yatırım seviyesinin yeşillik seviyesine birim etkisinin, merkezi, kontrat sonrası ve merkezkaç tedarik zincirlerinin toplam karı üzerindeki etkileri incelenmiştir. Sonuçlar, üreticinin Endüstri 4.0 yatırım seviyesinin yeşillik seviyesine birim etkisi arttıkça, tedarik zincirlerinin daha fazla kar elde ettiğini göstermektedir. Merkezi ve kontrat sonrası tedarik zincirleri bu artıştan nispeten daha fazla etkilenmektedir.

Şekil 2'de, üreticinin Endüstri 4.0 yatırım seviyesinin yeşillik seviyesine birim etkisinin, merkezi, kontrat sonrası ve merkezkaç tedarik zincirlerindeki üretici ve perakendecinin yeşillik seviyesi üzerindeki etkileri incelenmiştir. Sonuçlar, tüm tedarik zincirlerinde, üreticinin yeşillik seviyesinin bu artıştan önemli ölçüde ve pozitif yönde etkilendiğini göstermektedir. Bu etki, merkezi ve kontrat sonrasi sistemlerde daha da belirgindir. Üreticinin Endüstri 4.0 yatırım seviyesinin yeşillik seviyesine birim etkisi yaklaşı 0,33 seviyesine gelene kadar, perakendecinin yeşillik seviyesi üreticiye göre daha yüksektir. Bu değerden sonra ise üreticinin yeşillik seviyesi perakendecinin yeşillik seviyesinin üzerine çıkmaktadır. Bunun yanı sıra, perakendecinin yeşillik seviyesi de tüm tedarik zincirlerinde bir miktar artmaktadir.

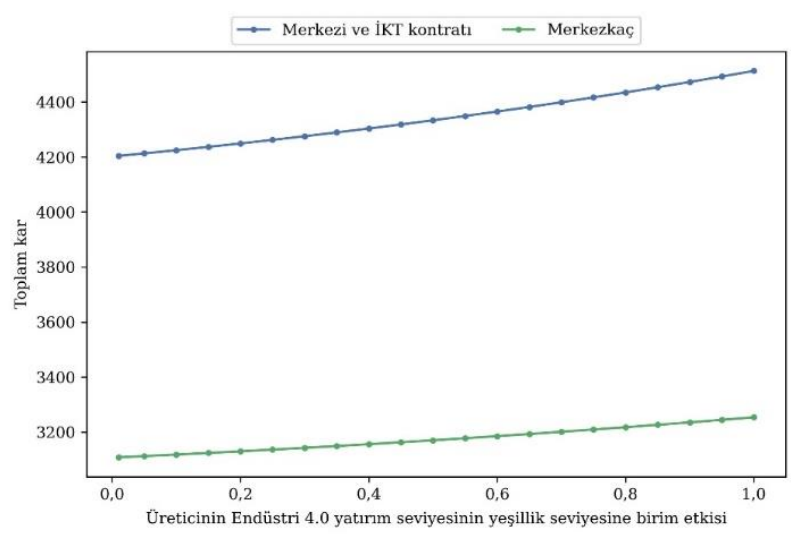

Şekil 1. Üreticinin Endüstri 4.0 yatırım seviyesinin yeşillik seviyesine birim etkisi / Toplam kar

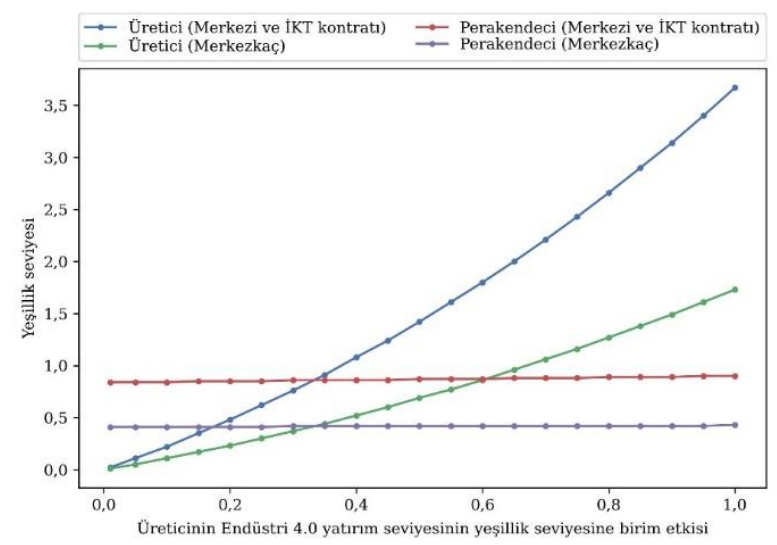

Şekil 2. Üreticinin Endüstri 4.0 yatırım seviyesinin yeşillik seviyesine birim etkisi / Yeşillik seviyesi
Şekil 3'te, üreticinin Endüstri 4.0 yatırım seviyesine bağlı birim maliyetindeki azalış miktarının, merkezi, kontrat sonrası ve merkezkaç tedarik zincirlerinin toplam karı üzerindeki etkileri incelenmiştir. Sonuçlar, üreticinin Endüstri 4.0 yatırım seviyesine bağlı birim maliyetindeki azalış miktarı arttıkça, tedarik zincirlerinin daha fazla kar elde ettiğini göstermektedir. Merkezi ve kontrat sonrası tedarik zincirleri bu artıştan nispeten daha fazla etkilenmektedir.

Şekil 4'te, üreticinin Endüstri 4.0 yatırım seviyesine bağlı birim maliyetindeki azalış miktarının, merkezi, kontrat sonrası ve merkezkaç tedarik zincirlerindeki üretici ve perakendecinin yeşillik seviyesi üzerindeki etkileri incelenmiştir. Sonuçlar, tüm tedarik zincirlerinde, üreticinin yeşillik seviyesinin bu artıştan önemli ölçüde ve pozitif yönde etkilendiğini göstermektedir. $\mathrm{Bu}$ etki, merkezi ve kontrat sonras1 sistemlerde daha da belirgindir. Üreticinin Endüstri 4.0 yatırım seviyesine bağlı birim maliyetindeki azalış miktarı yaklaşık 0,23 seviyesine gelene kadar, perakendecinin yeşillik seviyesi üreticiye göre daha yüksektir. Bu değerden sonra ise üreticinin yeşillik seviyesi perakendecinin yeşillik seviyesinin üzerine çıkmaktadır. Bunun yanı sıra, perakendecinin yeşillik seviyesi de tüm tedarik zincirlerinde bir miktar artmaktadır. Dolayısıyla, üreticinin yeşillik seviyesindeki artışın, perakendecinin de daha fazla yeşillik yatırımı yapmasını ve yeşillik seviyesini arttırmasını sağladığı söylenebilir.

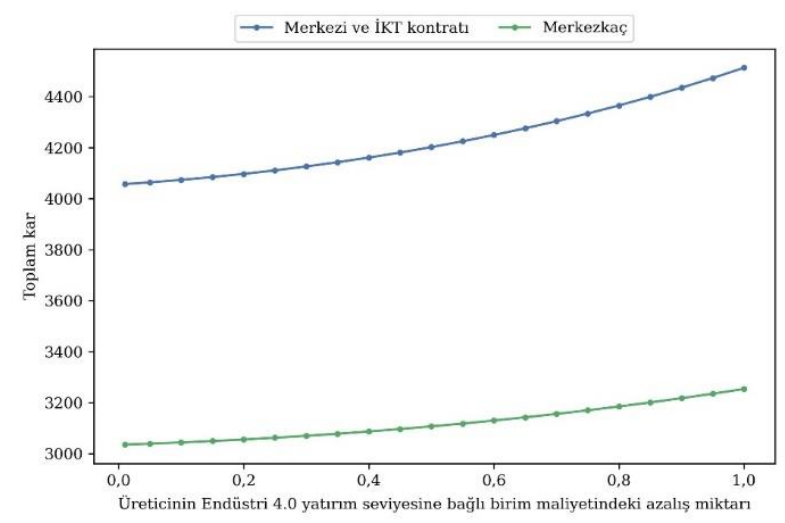

Şekil 3. Üreticinin Endüstri 4.0 yatırım seviyesine bağlı birim maliyetindeki azalış miktarı / Toplam kar

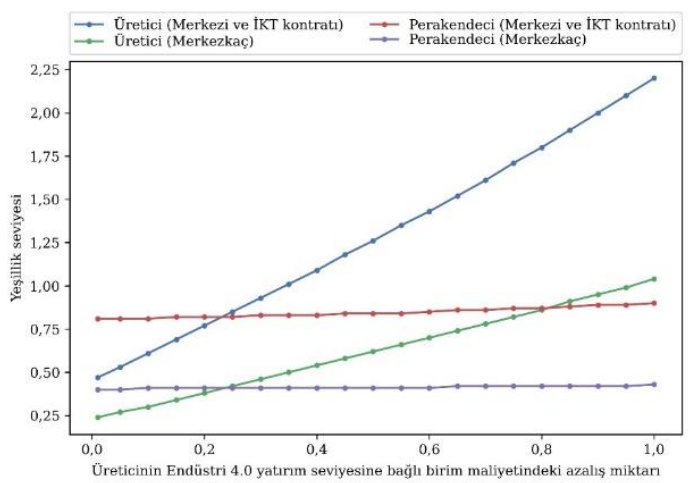

Şekil 4. Üreticinin Endüstri 4.0 yatırım seviyesine bağlı birim maliyetindeki azalış miktarı / Yeşillik seviyesi 
Şekil 1-4'te merkezi, kontrat sonrası ve merkezkaç sistemler karşılaştırıldığında, İKT kontratının merkezi sistemle aynı sonuçları verdiği, dolayısıyla tedarik zincirini koordine ettiği görülmektedir (Önerme 4). Merkezi ve kontrat sonrası sistemlere ait toplam kar ve yeşillik seviyeleri, merkezkaç sisteme göre daha yüksektir (Önerme 3a, 3b, 3e). Bu sonuç, koordinasyonun tedarik zincirlerinin ekonomik ve çevresel sürdürülebilirliği açısından önemini ortaya koymaktadır. Ayrıca, üreticinin Endüstri 4.0 yatırım seviyesinin yeşillik seviyesine birim etkisi ve/veya Endüstri 4.0 yatırım seviyesine bağlı birim maliyetindeki azalış miktarı arttıkça, tüm tedarik zincirlerinin hem ekonomik hem de çevresel boyutlarda daha fazla sürdürülebilir olduğu ortaya çıkmaktadır.

\section{SONUCCLAR}

Günümüzde çevresel koşulların gittikçe kötüye gitmesi nedeniyle, firmaların çevreye duyarlı üretim yapması ya da hizmet sunması önem kazanmaktadır. Bu bilinç tüketicileri de etkilemiş olup, yeşil ürünlere olan talep gün geçtikçe artmaktadır. Endüstri 4.0 teknolojilerinin de çevreye olumlu etkilerinin olduğu öngörülmektedir. $\mathrm{Bu}$ çalışma, Endüstri 4.0 teknolojileri uygulayan ve çevreye duyarlı bir pazara hizmet eden, iki aşamalı yeşil bir tedarik zincirinin koordinasyonunu ele almaktadır. Üreticinin Endüstri 4.0 yatırım miktarı, maliyetini ve yeşillik seviyesini etkilemektedir. Perakendeci de yeşillik seviyesini arttırmak için yatırım yapmaktadır. Tedarik zincirinin her bir üyesinin kendi sistemini optimize etmeyi amaçladı̆̆ı merkezkaç sistemde, üreticinin ve perakendecinin yeşillik seviyeleri optimal çözüme oranla daha düşük çıkmaktadır. Ayrıca, üreticinin Endüstri 4.0 yatırım seviyesi, talep ve tedarik zincirinin toplam karı da merkezkaç çözümde daha düşüktür. $\mathrm{Bu}$ sonuçlar, tedarik zincirinin koordine edilmesi gerektiğini ortaya koymaktadır. Bu amaçla, bu çalışmada İKT kontratı geliştirilmiştir.

IKT kontratında, üretici ürünleri maliyetine satmakta, perakendeci ise daha sonra üreticiye toplu bir ödeme yapmaktadır. Kontrat sonrasında hem üretici hem de perakendeci rasyonel olarak merkezi çözüm doğrultusunda karar vermektedir. Dolayısıyla, İKT kontrat1 tedarik zincirinin koordinasyonunu sağlamaktadır. Bunun yanı sıra, İKT kontratı aynı zamanda Pareto iyileştirendir. Ayrıca, kontrat parametreleri uygun olarak belirlendiğinde üyeler adil bir şekilde kar artışından faydalanabilmektedir. $\mathrm{Bu}$ bağlamda, IKKT kontratının üretici ve perakendeci tarafından kabul edilebilir ve uygulanabilir olduğu açıktır.

Kontrat öncesi ve sonrası tedarik zincirlerinin analiz edilmesi, koordinasyonun tedarik zincirlerinin ekonomik ve çevresel sürdürülebilirliği açısından önemini vurgulamaktadır. Elde edilen bu sonuç, literatürde yer alan bulgular $[10,12]$ ile de örtüşmektedir. Bunun yanı sıra, tedarik zincirlerinin koordine olması, Endüstri 4.0 teknolojilerine yapılan yatırımların artması açısından da önemlidir. Ayrıca, üreticinin Endüstri 4.0 yatırım seviyesinin yeşillik seviyesine birim etkisi ve/veya Endüstri 4.0 yatırım seviyesine bağlı birim maliyetindeki azalış miktarı arttıkça, tedarik zincirlerinin hem ekonomik hem de çevresel boyutlarda daha fazla sürdürülebilir olduğu ortaya çıkmaktadır. $\mathrm{Bu}$ çalışmadan elde edilen sonuçlar, tedarik zinciri üyelerinin etkileşim içinde olduğunu; üreticinin yeşillik seviyesindeki artışın, perakendecinin de daha fazla yeşillik yatırımı yapmasını sağladığını göstermektedir.

Bu makale, daha sürdürülebilir bir dünya için kolektif bilinç ve iş birliğinin gerekliliğini ortaya koymaktadır. $\mathrm{Bu}$ bağlamda, hükümetler, Endüstri 4.0 teknolojileri uygulayan ve/veya yeşillik yatırımları yapan firmalara destek vererek yatırım seviyelerini arttırmalarını sağlayabilir. Yapılacak teşvikler sayesinde, bu firmalar hem ekonomik hem de çevresel boyutlarda daha sürdürülebilir olacaktır.

Bu çalışma, Endüstri 4.0 yatırımı ile sürdürülebilirliğin ekonomik ve çevresel boyutlarını ilişkilendirmesi açısından kontrat literatüründeki önemli bir boşluğu doldurmaktadır. Üreticinin maliyetinin ve yeşillik seviyesinin Endüstri 4.0 yatırımına bağlı olarak modellenmesi ve her iki üyenin de yeşillik seviyesini arttırmak için yatırım yapması, bu makalede kurulan modeli diğer çalışmalardan ayırmaktadır. Bu çalışmayı farklı şekillerde geliştirmek mümkündür. Tedarik zinciri farklı bir oyun teorisi yaklaşımı ile analiz edilerek, üreticinin ya da perakendecinin Stackelberg lideri olduğu farklı oyunlar ele alınabilir. Bunun dışında, tedarik zincirinin koordinasyonu için gelir ya da maliyet paylaşımı gibi farklı kontratlar tasarlanarak, bu kontratların koordinasyon kabiliyetleri ve Pareto iyileştiren olup olmadıkları incelenebilir.

\section{TEŞEKKÜR}

Yazar, editörler ve hakemlere değerli katkıları için teşekkür eder. Bu çalışma, Doğuş Üniversitesi [Bilimsel Araştırma Projesi, Proje numarası: 2019-20D2-B09] tarafindan desteklenmiştir.

\section{EK A. ÍSPATLAR}

Önerme 1. Oyunun ikinci aşaması ile başlanır. Eşitlik (3)'te verilen tedarik zincirinin toplam kar fonksiyonu için Hessian matrisi

$$
H(p, \beta)=\left[\begin{array}{cc}
-2 b & g_{P} \\
g_{P} & -2 I
\end{array}\right]
$$

olarak bulunur. $H(p, \beta)$ matrisinin $k$. mertebe asal minörleri $\Delta_{1}=-2 b$ ve $\Delta_{2}=4 I b-g_{p}^{2} \quad$ şeklindedir. Varsayım 1a'ya göre ve $b>0$ olduğundan, tüm asal minörler için $(-1)^{k} \Delta_{k}>0$ olup, $H(p, \beta)$ matrisi 
negatif tanımlıdır. Dolayısıyla, $\pi_{T Z}(p, \beta, \alpha)$ fonksiyonu $(p, \beta)$ üzerinde kesin içbükeydir. $p$ ve $\beta$ 'ya göre birinci dereceden koşullar eş zamanlı çözüldüğünde tedarik zincirinin en iyi cevap fonksiyonu

$$
\begin{aligned}
& p^{\cdot}(\alpha)=\frac{2 I\left(a+b c+\left(g_{v} h_{1}-b h_{2}\right) \alpha\right)-g_{p}^{2}\left(c-h_{2} \alpha\right)}{4 I b-g_{p}^{2}}, \\
& \beta^{*}(\alpha)=\frac{g_{P}\left(a-b c+\left(g_{U} h_{1}+b h_{2}\right) \alpha\right)}{4 I b-g_{P}^{2}}
\end{aligned}
$$

olarak elde edilir. Ardından, Eşitlik (A1) ve (A2), Eşitlik (3)'te yerine konulur. Buna göre, Varsayım 1a uyarınca, $\pi_{T Z}\left(p^{*}(\alpha), \beta^{*}(\alpha), \alpha\right)$ fonksiyonunun $\alpha$ 'ya göre ikinci dereceden türevi

$$
\frac{\partial^{2} \pi_{T z}\left(p^{*}(\alpha), \beta^{*}(\alpha), \alpha\right)}{\partial \alpha^{2}}=\frac{2 I\left(g_{U} h_{1}+b h_{2}\right)^{2}}{4 I b-g_{P}^{2}}-2 E<0
$$

olarak bulunur. Dolayısıyla, $\pi_{T Z}\left(p^{*}(\alpha), \beta^{*}(\alpha), \alpha\right)$ fonksiyonu $\alpha$ üzerinde kesin içbükeydir. $\alpha$ 'ya göre birinci dereceden koşul çözüldüğünde, Eşitlik (6) elde edilir. Eşitlik (6), Eşitlik (A1) ve (A2)'de yerine konularak Eşitlik (4) ve (5) bulunur. Son olarak, Eşitlik (4)-(6), Eşitlik (3) ve $D=a-b p+g_{P} \beta+g_{U} h_{1} \alpha$ fonksiyonunda yerine konulduğunda, Eşitlik (7) ve (8) elde edilir.

Önerme 2. Perakendecinin merkezkaç modeli ile başlanır. Eşitlik (1)'de verilen perakendecinin kar fonksiyonu için Hessian matrisi

$$
H(p, \beta)=\left[\begin{array}{cc}
-2 b & g_{P} \\
g_{P} & -2 I
\end{array}\right]
$$

olarak bulunur. $H(p, \beta)$ matrisinin $k$. mertebe asal minörleri $\Delta_{1}=-2 b$ ve $\Delta_{2}=4 I b-g_{p}^{2} \quad$ şeklindedir. Varsayım 1a'ya göre ve $b>0$ olduğundan, tüm asal minörler için $(-1)^{k} \Delta_{k}>0$ olup, $H(p, \beta)$ matrisi negatif tanımlıdır. Dolayısıyla, $\pi_{P}(p, \beta)$ fonksiyonu kesin içbükeydir. $p$ ve $\beta$ 'ya göre birinci dereceden koşullar eş zamanlı çözüldüğünde perakendecinin en iyi cevap fonksiyonu

$$
\begin{aligned}
& p^{m}(w, \alpha)=\frac{2 I\left(a+b w+g_{U} h_{1} \alpha\right)-g_{P}^{2} w}{4 I b-g_{P}^{2}}, \\
& \beta^{m}(w, \alpha)=\frac{g_{P}\left(a-b w+g_{U} h_{1} \alpha\right)}{4 I b-g_{P}^{2}}
\end{aligned}
$$

olarak elde edilir. Ardından, üreticinin problemi ele alınır. Eşitlik (A3) ve (A4), Eşitlik (2)'de yerine konulur. Buna göre, Eşitlik (2)'de verilen üreticinin kar fonksiyonu için Hessian matrisi

$$
H(w, \alpha)=\left[\begin{array}{cc}
-\frac{4 I b^{2}}{4 I b-g_{P}^{2}} & \frac{2 I b\left(g_{U} h_{1}-b h_{2}\right)}{4 I b-g_{P}^{2}} \\
\frac{2 I b\left(g_{U} h_{1}-b h_{2}\right)}{4 I b-g_{P}^{2}} & \frac{4 I b g_{U} h_{1} h_{2}}{4 I b-g_{P}^{2}}-2 E
\end{array}\right]
$$

olarak bulunur. $H(w, \alpha)$ matrisinin $k$. mertebe asal minörleri

$$
\Delta_{1}=-\frac{4 I b^{2}}{4 I b-g_{P}^{2}}
$$

$\Delta_{2}=\frac{4 I b^{2}\left(2 E\left(4 I b-g_{P}^{2}\right)-I\left(g_{U} h_{1}+b h_{2}\right)^{2}\right)}{\left(4 I b-g_{P}^{2}\right)^{2}}$ şeklindedir.

Varsayım 1a'ya göre ve $I>0$ olduğundan, tüm asal minörler için $(-1)^{k} \Delta_{k}>0$ olup, $H(w, \alpha)$ matrisi negatif tanımlıdır. Dolayısıyla, $\pi_{U}(w, \alpha)$ fonksiyonu kesin içbükeydir. $w$ ve $\alpha$ 'ya göre birinci dereceden koşullar eş zamanlı çözüldüğünde, Eşitlik (11) ve (12) elde edilir. Eşitlik (11) ve (12), Eşitlik (A3) ve (A4)'te yerine konularak Eşitlik (9) ve (10) bulunur. Son olarak, Eşitlik (9)-(12), Eşitlik (3) ve $D=a-b p+g_{P} \beta+g_{U} h_{1} \alpha \quad$ fonksiyonunda yerine konulduğunda, Eşitlik (13) ve (14) elde edilir.

Önerme 3. Bu önermede yer alan bulgular basit cebirsel kıyaslamalar sonucunda elde edilmiştir.

a. Varsayım 1'e göre ve $b>0, g_{U}>0, h_{1}>0, h_{2}>0$, $I>0, \quad \theta=h_{1} \alpha$ olduğundan, Eşitlik (6) ve (12)'nin kıyaslanması sonucunda elde edilir.

b. Varsayım 1'e göre ve $E>0, g_{P}>0$ olduğundan, Eşitlik (5) ve (10)'un kıyaslanması sonucunda elde edilir.

c. Varsayım 1'e göre, Eşitlik (4) ve (9)'un kıyaslanması sonucunda elde edilir.

d. Varsayım 1'e göre ve $b>0, \quad E>0, \quad I>0$ olduğundan, Eşitlik (8) ve (14)'ün kıyaslanması sonucunda elde edilir.

e. Varsayım 1a'ya göre ve $E>0, \quad I>0$ olduğundan, Eşitlik (7) ve (13)'ün kıyaslanması sonucunda elde edilir.

Önerme 4. Perakendecinin merkezkaç modeli ile başlanır. Eşitlik (17), Eşitlik (15)'te yerine konulur. Buna göre, Eşitlik (15)'te verilen perakendecinin kontrat sonrası kar fonksiyonu için Hessian matrisi

$H(p, \beta)=\left[\begin{array}{cc}-2 b & g_{P} \\ g_{P} & -2 I\end{array}\right]$

olarak bulunur. $H(p, \beta)$ matrisinin $k$. mertebe asal minörleri $\Delta_{1}=-2 b$ ve $\Delta_{2}=4 I b-g_{p}^{2} \quad$ şeklindedir. Varsayım 1a'ya göre ve $b>0$ olduğundan, tüm asal 
minörler için $(-1)^{k} \Delta_{k}>0$ olup, $H(p, \beta)$ matrisi negatif tanımlıdır. Dolayısıyla, $\pi_{p}^{T}(p, \beta)$ fonksiyonu kesin içbükeydir. $p$ ve $\beta$ 'ya göre birinci dereceden koşullar eş zamanlı çözüldüğünde perakendecinin en iyi cevap fonksiyonu

$$
\begin{aligned}
& p^{T}(w, \alpha)=\frac{2 I\left(a+b w+g_{U} h_{1} \alpha-k_{1}\right)-g_{P}^{2} w-g_{P} k_{2}}{4 I b-g_{P}^{2}}, \\
& \beta^{T}(w, \alpha)=\frac{g_{P}\left(a-b w+g_{U} h_{1} \alpha-k_{1}\right)-2 b k_{2}}{4 I b-g_{P}^{2}}
\end{aligned}
$$

olarak elde edilir. Ardından, üreticinin problemi ele alınır. Eşitlik (A5), (A6) ve (17), Eşitlik (16)'da yerine konulur. Buna göre, Eşitlik (16)'da verilen üreticinin kontrat sonrası kar fonksiyonu için Hessian matrisi

$$
H(w, \alpha)=\left[\begin{array}{cc}
-\frac{4 I b^{2}}{4 I b-g_{p}^{2}} & \frac{2 I b\left(g_{U} h_{1}-b h_{2}\right)}{4 I b-g_{p}^{2}} \\
\frac{2 I b\left(g_{U} h_{1}-b h_{2}\right)}{4 I b-g_{p}^{2}} & \frac{4 I b g_{U} h_{1} h_{2}}{4 I b-g_{p}^{2}}-2 E
\end{array}\right]
$$

olarak bulunur. $H(w, \alpha)$ matrisinin $k$. mertebe asal

$$
\text { minörleri } \quad \Delta_{1}=-\frac{4 I b^{2}}{4 I b-g_{P}^{2}} \quad \text { ve }
$$

$\Delta_{2}=\frac{4 I b^{2}\left(2 E\left(4 I b-g_{P}^{2}\right)-I\left(g_{U} h_{1}+b h_{2}\right)^{2}\right)}{\left(4 I b-g_{P}^{2}\right)^{2}}$ şeklindedir.

Varsayım 1a'ya göre ve $I>0$ olduğundan, tüm asal minörler için $(-1)^{k} \Delta_{k}>0$ olup, $H(w, \alpha)$ matrisi negatif tanımlıdır. Dolayısıyla, $\pi_{U}^{T}(w, \alpha)$ fonksiyonu kesin içbükeydir. $w$ ve $\alpha$ 'ya göre birinci dereceden koşullar eş zamanlı çözüldüğünde, Eşitlik (6) ve $w^{T}=c-h_{2} \alpha^{*}+\frac{E \alpha^{* 2}}{D^{*}}$ elde edilir. Eşitlik (6) ve $w^{T}$, Eşitlik (A5) ve (A6)'da yerine konularak Eşitlik (4) ve (5) bulunur. Bulunan çözüm merkezi çözüme eşit olduğundan, İKT kontratı tedarik zincirini koordine etmektedir. $\square$

Önerme 5. İKT kontratının Pareto iyileştiren olması için, her iki üyenin kontrat sonrası karı merkezkaç sistemdeki karı ile aynı ya da daha yüksek olmalıdır. $w^{T}=c-h_{2} \alpha+\frac{E \alpha^{2}}{D}$, Önerme 1'de verilen merkezi çözüm ve Eşitlik (17), Eşitlik (15)’te yerine konularak perakendecinin kontrat sonrası karı

$\pi_{p}^{T}=\frac{I\left(2 E b(a+b c)-a\left(g_{v} h_{1}+b h_{2}\right)^{2}\right)(a-b c)}{2 b\left(E\left(4 I b-g_{P}^{2}\right)-I\left(g_{v} h_{1}+b h_{2}\right)^{2}\right)}-\varepsilon$ olarak bulunur. Perakendecinin kontrat öncesi karı ise, Önerme 2'de verilen merkezkaç çözüm, Eşitlik (1)'de yerine konularak aşağıdaki şekilde elde edilir:

$$
\pi_{P}^{m}=\frac{E^{2} I\left(4 I b-g_{P}^{2}\right)(a-b c)^{2}}{\left(2 E\left(4 I b-g_{P}^{2}\right)-I\left(g_{U} h_{1}+b h_{2}\right)^{2}\right)^{2}} .
$$

Buna göre, $\pi_{p}^{T} \geq \pi_{p}^{m}$ koşulu uyarınca Eşitlik (18) bulunur. Benzer şekilde, $w^{T}=c-h_{2} \alpha+\frac{E \alpha^{2}}{D}$, Önerme 1'de verilen merkezi çözüm ve Eşitlik (17), Eşitlik (16)'da yerine konularak üreticinin kontrat sonrası karı

$\pi_{v}^{T}=\frac{I\left(a\left(g_{v} h_{1}+b h_{2}\right)^{2}-4 E b^{2} c\right)(a-b c)}{2 b\left(E\left(4 I b-g_{P}^{2}\right)-I\left(g_{v} h_{1}+b h_{2}\right)^{2}\right)}+\varepsilon$

olarak bulunur. Üreticinin kontrat öncesi karı ise, Önerme 2'de verilen merkezkaç çözüm, Eşitlik (2)'de yerine konularak aşağıdaki şekilde elde edilir:

$\pi_{U}^{m}=\frac{E I(a-b c)^{2}}{2 E\left(4 I b-g_{P}^{2}\right)-I\left(g_{U} h_{1}+b h_{2}\right)^{2}}$.

Buna göre, $\pi_{U}^{T} \geq \pi_{U}^{m}$ koşulu uyarınca Eşitlik (19) bulunur. Eşitlik (18) ve (19), her iki üyenin de kontrat sonras1 karının azalmamasını garanti etmektedir. Bunun yanı sıra, Önerme $3 \mathrm{e}$ ve 4'e göre, $\pi_{P}^{T}+\pi_{U}^{T}>\pi_{P}^{m}+\pi_{U}^{m}$ olduğu açıktır. Dolayısıyla, $\varepsilon$ tam sınır değerde alınsa dahi, üyelerden birinin karı kontrat sonrasında aynı kalırken diğer üyenin karı artmaktadır. Sonuç olarak, İKT kontratı ancak ve ancak Eşitlik (18) ve (19)'da verilen koşulların sağlanması durumunda Pareto iyileştirendir.

\section{KAYNAKLAR}

[1] Rüßmann, M., Lorenz, M., Gerbert, P., Waldner, M., Justus, J., Engel, P. ve Harnisch, M. (2015). Industry 4.0: The future of productivity and growth in manufacturing industries. BCG Perspective.

[2] World Economic Forum. (2019). Supply Chain 4.0 Global Practices and Lessons Learned for Latin America and the Caribbean, The Economic Impact of Artificial Intelligence on the UK Economy - PWC.

[3] Kersten, W., Seiter, M., von See, B., Hackius, N. ve Maurer, T. (2017). Trends and strategies in logistics and supply chain management: Digital transformation opportunities, DVV Media Group GmbH.

[4] Strandhagen, J.O., Vallandingham, L.R., Fragapane, G., Strandhagen, J.W., Stangeland, A.B.H. ve Sharma, N. (2017). Logistics 4.0 and emerging sustainable business models. Adv. Manuf. 5, 359-369. 
[5] Bai, C., Dallasega, P., Orzes, G. ve Sarkis, J. (2020). Industry 4.0 technologies assessment: A sustainability perspective. Int. J. Prod. Econ. 229.

[6] Mastos, T.D., Nizamis, A., Vafeiadis, T., Alexopoulos, N., Ntinas, C., Gkortzis, D., Papadopoulos, A., Ioannidis, D. ve Tzovaras, D. (2020). Industry 4.0 sustainable supply chains: An application of an IoT enabled scrap metal management solution. J. Clean. Prod. 269.

[7] Dempsey, N., Bramley, G., Power, S. ve Brown, C. (2011). The social dimension of sustainable development: Defining urban social sustainability. Sustain. Dev. 19, 289-300.

[8] Stock, T., Obenaus, M., Kunz, S. ve Kohl, H. (2018). Industry 4.0 as enabler for a sustainable development: A qualitative assessment of its ecological and social potential. Process Saf. Environ. Prot. 118, 254-267.

[9] Ghobakhloo, M. (2020). Industry 4.0, digitization, and opportunities for sustainability. J. Clean. Prod. 252.

[10] Chen, L., Zhao, X., Tang, O., Price, L., Zhang, S. ve Zhu, W. (2017). Supply chain collaboration for sustainability: A literature review and future research agenda. Int. J. Prod. Econ. 194, 73-87.

[11] World Economic Forum. (2019). Business Models Inspired by Nature are the Future. https://www.weforum.org/agenda/2019/09/busi ness-models-inspired-by-nature-are-the-future.

[12] Singh, R.K., Kumar, P. ve Chand, M. (2021). Evaluation of supply chain coordination index in context to Industry 4.0 environment. Benchmarking: An International Journal 28, 5, 1622-1637.

[13] Toktaş-Palut, P. ve Ülengin, F. (2011). Coordination in a two-stage capacitated supply chain with multiple suppliers. Eur. J. Oper. Res. 212, 43-53.

[14] Cachon, G.P. (2003). Supply Chain Coordination with Contracts. Handbooks Oper. Res. Manag. Sci.

[15] Govindan, K., Popiuc, M.N. ve Diabat, A. (2013). Overview of coordination contracts within forward and reverse supply chains. J. Clean. Prod. 47, 319-334.

[16] Chauhan, C. ve Singh, A. (2018). Modeling green supply chain coordination: current research and future prospects. Benchmarking: An International Journal 25, 9, 3767-3788.

[17] Bart, N., Chernonog, T. ve Avinadav, T. (2019). Revenue sharing contracts in a supply chain: A literature review. IFAC-PapersOnLine 52, 1578-1583.

[18] Zhu, W. ve He, Y. (2017). Green product design in supply chains under competition. Eur. J. Oper. Res. 258, 165-180.

[19] Ghosh, D. ve Shah, J. (2015). Supply chain analysis under green sensitive customer demand and cost sharing contract. Int. J. Prod. Econ. 164, 319-329.

[20] Yenipazarli, A. (2017). To collaborate or not to collaborate: Prompting upstream eco-efficient innovation in a supply chain. Eur. J. Oper. Res. 260, 571-587.

[21] Peng, H., Pang, T. ve Cong, J. (2018). Coordination contracts for a supply chain with yield uncertainty and low-carbon preference. J. Clean. Prod. 205, 291-302.

[22] Song, H. ve Gao, X. (2018). Green supply chain game model and analysis under revenue-sharing contract. J. Clean. Prod. 170, 183-192.

[23] Panja, S. ve Mondal, S.K. (2020). Exploring a two-layer green supply chain game theoretic model with credit linked demand and mark-up under revenue sharing contract. J. Clean. Prod. 250.

[24] Ghosh, D. ve Shah, J. (2012). A comparative analysis of greening policies across supply chain structures. Int. J. Prod. Econ. 135, 568-583.

[25] Li, B., Zhu, M., Jiang, Y. ve Li, Z. (2016). Pricing policies of a competitive dual-channel green supply chain. J. Clean. Prod. 112, 2029-2042.

[26] Ni, D., Li, K.W. ve Tang, X. (2010). Social responsibility allocation in two-echelon supply chains: Insights from wholesale price contracts. Eur. J. Oper. Res. 207, 1269-1279.

[27] Panda, S. (2014). Coordination of a socially responsible supply chain using revenue sharing contract. Transp. Res. Part E Logist. Transp. Rev. 67, 92-104.

[28] Raj, A., Biswas, I. ve Srivastava, S.K. (2018). Designing supply contracts for the sustainable supply chain using game theory. J. Clean. Prod. $185,275-284$.

[29] Heydari, J. ve Rafiei, P. (2020). Integration of environmental and social responsibilities in managing supply chains: A mathematical modeling approach. Comput. Ind. Eng. 145.

[30] Raj, A., Modak, N.M., Kelle, P. ve Singh, B. (2021). Analysis of a dyadic sustainable supply chain under asymmetric information. Eur. J. Oper. Res. 289, 582-594.

[31] Xu, J., Chen, Y. ve Bai, Q. (2016). A two-echelon sustainable supply chain coordination under cap-and-trade regulation. J. Clean. Prod. 135, $42-56$.

[32] Liu, Z., Zheng, X.X., Gong, B.G. ve Gui, Y.M. (2017). Joint decision-making and the coordination of a sustainable supply chain in the context of carbon tax regulation and fairness concerns. Int. J. Environ. Res. Public Health 14.

[33] Qian, X., Chan, F.T.S., Zhang, J., Yin, M. ve Zhang, Q. (2020). Channel coordination of a two-echelon sustainable supply chain with a fair-minded retailer under cap-and-trade regulation. J. Clean. Prod. 244.

[34] Bai, Q., Xu, J. ve Chauhan, S.S. (2020). Effects of sustainability investment and risk aversion on a 
two-stage supply chain coordination under a carbon tax policy. Comput. Ind. Eng. 142.

[35] Panda, S., Modak, N.M., Basu, M. ve Goyal, S.K. (2015). Channel coordination and profit distribution in a social responsible three-layer supply chain. Int. J. Prod. Econ. 168, 224-233.

[36] Modak, N.M., Panda, S., Mishra, R. ve Sana, S.S. (2016). A three-layer supply chain coordination in socially responsible distribution system. Tékhne 14, 75-87.

[37] Huang, R. ve Yao, X. (2021). An analysis of sustainability and channel coordination in a three-echelon supply chain. J. Enterp. Inf. Manag. 34, 1, 490-505.

[38] Toktaş-Palut, P. (2021). An integrated contract for coordinating a three-stage green forward and reverse supply chain under fairness concerns. J. Clean. Prod. 279.

[39] Ghosh, D., Sant, T.G., Kuiti, M.R., Swami, S. ve Shankar, R. (2020). Strategic decisions, competition and cost-sharing contract under industry 4.0 and environmental considerations. Resour. Conserv. Recycl. 162.

[40] Ma, X., Wang, J., Bai, Q. ve Wang, S. (2020). Optimization of a three-echelon cold chain considering freshness-keeping efforts under cap-and-trade regulation in Industry 4.0. Int. J. Prod. Econ. 220.

[41] Kamble, S.S., Gunasekaran, A. ve Gawankar, S.A. (2018). Sustainable Industry 4.0 framework: A systematic literature review identifying the current trends and future perspectives. Process Saf. Environ. Prot. 117, 408-425.
[42] Ramadan, M., Al-Maimani, H. ve Noche, B. (2017). RFID-enabled smart real-time manufacturing cost tracking system. Int. J. Adv. Manuf. Technol. 89, 969-985.

[43] Sanders, A., Elangeswaran, C. ve Wulfsberg, J. (2016). Industry 4.0 implies lean manufacturing: Research activities in industry 4.0 function as enablers for lean manufacturing. J. Ind. Eng. Manag. 9, 811-833.

[44] Banker, R.D., Khosla, I. ve Sinha, K.K. (1998). Quality and competition. Manage. Sci. 44, 1179-1192.

[45] Ford, S. ve Despeisse, M. (2016). Additive manufacturing and sustainability: an exploratory study of the advantages and challenges. J. Clean. Prod. 137, 1573-1587.

[46] Beier, G., Niehoff, S., Ziems, T. ve Xue, B. (2017). Sustainability aspects of a digitalized industry - A comparative study from China and Germany. Int. J. Precis. Eng. Manuf. - Green Technol. 4, 227-234.

[47] Müller, J.M., Kiel, D. ve Voigt, K.I. (2018). What drives the implementation of Industry 4.0? The role of opportunities and challenges in the context of sustainability. Sustainability 10, 247.

[48] Sarkis, J. ve Zhu, Q. (2018). Environmental sustainability and production: taking the road less travelled. Int. J. Prod. Res. 56, 743-759.

[49] Stock, T., Obenaus, M., Kunz, S. ve Kohl, H. (2018). Industry 4.0 as enabler for a sustainable development: A qualitative assessment of its ecological and social potential. Process Saf. Environ. Prot. 118, 254-267. 